\title{
Efektifitas Executive Coaching Pada Tipe Kepemimpinan Transformasional dan Transaksional
}

\author{
Rauly Sijabat ${ }^{1}, * \&$ Pramudianto $^{2}$ \\ ${ }^{1}$ Program Studi Manajemen, Fakultas Ekonomi dan Bisnis, Universitas PGRI Semarang \\ ${ }^{2}$ Badan Pendidikan Kristen (BPK) Penabur, Jakarta \\ *Email: raulysijabat@upgris.ac.id
}

\begin{abstract}
Executive coaching that considers leadership types has the potential to change behavior that can improve individual and organizational performance. This is what prompted a study to determine the effectiveness of giving executive coaching on the types of transformational and transactional leadership.The design of the study designed in this study is mixed-factorial design $2 x 2$ between-within subject. The first factor is executive coaching which consists of two levels, namely executive coaching and no executive coaching and the second factor is the type of leadership which consists of two levels, namely transformational and transactional on proactive influence tactics rational persuasion, inspirational appeals, consultation, collaboration. The data measured or observed in this study is the sales performance of the experimental participants consisting of sales heads and key account heads in automotive multinational companies. The findings of this study indicate that this type of transformational leadership with executive coaching has proven to be more effective in improving sales head and key account head sales performance. Furthermore, this study also shows that in the type of transformational leadership, the proactive collaboration and consultation influence tactics proved to be more effective while the transactional leadership type will be more effective in proactive rational and inspirational tactics.
\end{abstract}

\begin{abstract}
Abstraksi: Executive coaching yang mempertimbangkan tipe kepemimpinan berpotensi mengubah kinerja personal maupun organisasi melalui perbaikan perilaku kerja. Fenomena ini menjadi pendorong dilakukannya penelitian bagaimana menentukan efektivitas memberikan executive coaching pada jenis kepemimpinan transformasional dan transaksional. Penelitian ini menggunakan rancangan faktorial campuran $2 \times 2$ antara-dalam subjek. Faktor pertama yaitu executive coaching meliputi dua tingkatan, yaitu executive coaching dan tanpa executive coaching dan faktor kedua adalah jenis kepemimpinan juga terdiri dari dua tingkat, yaitu transformasional dan transaksional pada taktik pengaruh proaktif, persuasi rasional, banding inspirasional, konsultasi, kolaborasi. Penelitian ini menggunakan data kinerja penjualan sebagai data yang terukur dan teramati yang didapat dari peserta eksperimental yang terdiri dari sales heads dan key account heads di perusahaan otomottif multinasional. Temuan penelitian ini menunjukkan bahwa jenis kepemimpinan transformasional dengan executive coaching telah terbukti memiliki efektifitas yang lebih baik dalam meningkatkan luaran kerja kepala penjualan. Penelitian ini juga menunjukkan bahwa dalam tipe kepemimpinan transformasional, kolaborasi proaktif dan taktik pengaruh konsultasi terbukti memiliki efektifitas yang lebih baik sedangkan tipe kepemimpinan transaksional memiliki efektifitas lebih baik dalam taktik rasional dan inspirasional yang proaktif.
\end{abstract}

Keywords: Executive Coaching; Transformational Leadership; Transactional Leadership

\section{Pendahuluan}

Riset mengenai executive coaching mengalami perkembangan yang pesat (Filipezak 1998; Kilburg 1996; Qucik dan Macik-Frey 2004; Feldman dan Lankau 2005; Nieminen 2013). Perkembangan literatur executive coaching di bidang konsultasi manajemen, pelatihan dan pengembangan serta konsultasi psikologi juga mengalami peningkatan (KampaKokesch dan Anderson 2001). Joo (2005) menyatakan bahwa riset executive coaching berelasi dengan mentoring, kesuksesan karir, balikan (feedback) 360 derajat serta pelatihan dan pembelajaran. Dalam kerangka konseptualnya, Joo (2005) menyajikan anteseden dari keberhasilan executive coaching adalah karakteristik coach, karakteristik coachee dan dukungan organisasi. Anteseden tersebut mengikuti proses pendekatan, hubungan dan penerimaan feedback dari coaching sehingga 
menghasilkan outcome berupa selfawareness dan pembelajaran. Hasil akhirnya adalah kesuksesan individual dan organisasi.

Kochanowski et al. (2010) menemukan bahwa manager yang berpartisipasi dalam workshop dan diberi feedback sebagai bentuk executive coaching mengalami peningkatan dalam hal kolaborasi. Dampak lainnya, executive coaching meningkatkan strategi komunikasi persuasif. Niemenen et al. (2013) juga memberikan bukti empiris yang sama bahwa executive coaching dengan MSF dalam workshop meningkatkan kinerja individual coachee. Sayangnya, kemampuan generalisasi pada kesimpulan penelitianpenelitian tersebut (Niemenen et al., 2013; Kochanowski et al., 2010) masih terbatas karena tipe kepemimpinan coach yang terlibat executive coaching belum diteliti lebih mendalam. Padahal tipe kepemimpinan memegang peranan penting dalam suatu organisasi. Tipe kepemimpinan penting dalam peran seorang coach, dikarenakan mempengaruhi dalam cara berkomunikasi dan relationship, yang akhirnya membawa dampak pada "trust" seorang coache terhadap coach-nya.

Tipe kepemimpinan dalam studi executive coaching perlu dikaji mengingat adanya hubungan antara perilaku dan keterampilan kepemimpinan berdampak positif terhadap efektivitas organisasi, hal ini terkait erat dengan nilai-nilai, norma-norma perilaku, dan praktik kerja (Denison dan Mishra, 1995; Denison, Nieminen, dan Kotrba, 2003). Penggunaan feedback terhadap perubahan perilaku dengan mempertimbangkan tipe kepemimpinan berpotensi dapat meningkatkan kinerja individual dan dampak akhirnya mencapai kinerja organisasional.

Terdorong oleh temuan celah penelitian bahwa penelitian-penelitian mengenai executive coaching belum melibatkan tipe kepemimpinan, maka penelitian ini bertujuan untuk melakukan kajian mengenai efektifitas executive coaching yang diberikan kepada bawahan dengan mempertimbangkan dua tipe kepemimpinan, yaitu kepemimpinan transformasional dan kepemimpinan transaksional.

\section{Kajian Teori dan Pengembangan Hipotesis}

\section{Kepemimpinan}

$\begin{array}{lcr}\text { Koontz dan Weihrich (1990) } \\ \text { menyatakan bahwa } & \text { kepemimpinan } \\ \text { merupakan kemampuan yang bersifat } \\ \text { dinamis untuk dapat mempengaruhi }\end{array}$ kelompok-kelompok dalam rangka mencapai tujuan prestasi. Kepemimpinan oleh Robbins (2008) dinyatakan sebagai kemampuan yang dimiliki oleh individu untuk mempengaruhi kelompok dalam mencapai tujuan-tujuan organisasi.

Mengacu pada pengertian tersebut, Hackman \& Walton (1986), Kozlowski et al (1996) dan Cohen \& Bailey (1997) menyatakan bahwa kepemimpinan merupakan faktor penting serta menjadi faktor kritis (Sinclair, 1992; Zaccaro et al, 2001) dalam memfasilitasi keefektifan tim organisasi.

Dua tipe kepemimpinan yang dipopulerkan oleh Bass (1990) di tahun 1980-an dan 1990-an adalah kepemimpinan transformasional dan kepemimpinan transaksional.

\section{Kepemimpinan Transformasional}

Kepemimpinan transformasional menurut Curpi (2012) merupakan tipe kepemimpinan yang mengedepankan tercapainya visi dan value perusahaan melalui kerja keras. Kepemimpinan transformasional merupakan tipe kepemimpinan yang mengedepankan pemotivasian bawahan dan upaya peningkatan semangat individu dalam bekerja serta pemberian dorongan pada upaya untuk mengutamakan pencapaian tujuan organisasi (Irawati dan Liana, 2013; Pradana, 2013; Muhardi dan Siregar, 2013). Robbins (2008) menyatakan bahwa kharismatik, inspiratif, pemberian stimulasi serta pertimbangan individu merupakan karakteristik-karakteristik yang dapat dilihat pada perilaku jenis kepemimpinan transformasional. 
Kepemimpinan Transaksional

Menurut Locander et al (2002), kepemimpinan transaksional yang memberikan motivasi karyawan dengen mengedepankan kepentingan-kepentingan pribadi. Kepemimpinan transaksional merupakan kepemimpinan yang dominan memberikan panduan kepada bawahan, memberikan reward and punishment atas pencapaian kinerja individu serta focus pada perilaku individu yang memandu bawahan dengan memperjelas tuntutan dan peran tugas (Maulizar et al, 2012). Imbalan kontingen, manajemen yang merujuk pada pengecualian aktif-pasif serta laissez-faire merupakan perilaku-perilaku yang sering ditunjukkan pada kepemimpinan transaksional (Robbins, 2008).

\section{Perbedaan Tipe Kepemimpinan Transformasional dan Transaksional}

Dalam transformational leadership, memberikan fokus yaitu membuat seseorang atau kelompok memiliki kesadaran yang lebih baik tentang tentang capaian pekerjaan, memberikan dorongan kepada karyawan untuk menjadikan kepentingan organisasi di atas kepentingan personal, dan mendorong kebutuhan karyawan menjadi lebih tinggi. Sedangkan transactional leadership berfokus pada keinginan bawahan dan berusaha memenuhi harapannya, melakukan imbalan yang mereka inginkan, melakukan respon terhadap kepentingan pribadi sepanjang mendukung tujuan perusahaan. Fokus yang memiliki kedua tipe kepemimpinan tersebut prosesnya berbeda, sehingga jika dilakukan secara konsisten, maka tipe kepemimpinan berdampak terhadap pengembangan karyawan.

Perilaku yang dilakukan pemimpin mampu memengaruhi kepuasan dan kinerja dari karyawannya (Yukl 2005, Pierce dan Newstrom, 2006). Challagalla dan Shervani (2006) dalam studinya mendapati kepuasan yang kuat pada karyawan dijelaskan oleh kepemimpinan. Penelitian Bogler (2001) juga mendapati bahwa kepemimpinan transformasional mampu mendorong meningkatnya motivasi, komitmen maupun kepuasan kerja (Koh, 1990). Kepemimpinan transformasional adalah merupakan suatu pendekatan yang dianggap efektif dalam proses atau sistem pendidikan (Leithwood, 1994).

$\mathrm{H}_{1}$ : Taktik pengaruh proaktif kepala penjualan dengan tipe kepemimpinan transformasional lebih baik dibandingkan dengan taktik pengaruh proaktif kepala penjualan dengan tipe kepemimpinan transaksional

Efektivitas Pemberian Executive Coaching pada Tipe Kepemimpinan Transformasional

Coaching memfokuskan pada penyiapan karyawan dengan kualitas yang tinggi dalam pengembangan karirnya (McCauley dan Hezlet 2002). Coaching adalah suatu seni membantu orang-orang meningkatkan keefektifan mereka dengan usaha untuk memberdayakan - mendampingi yang dilakukan tak langsung (non-directive) pada coachee dan melakukan kepemimpinan dari belakang (leading from behind). Dengan pemahaman tersebut maka executive coaching mampu meningkatkan kualitas para manajer, karena ada proses efektifitas dalam pendampingan dan menggunakan metoda yang jelas.

Studi Nieminen et al. (2013) menunjukkan adanya peningkatan hasil kerja manajer yang memperoleh executive coaching bila dibandingkan dengan luaran kerja manajer yang tidak memperoleh executive coaching. Seifert et al. (2003) yang memberi bukti empiris bahwa manajer yang berpartisipasi dalam suatu feedback workshop menunjukkan peningkatan dalam hal taktik konsultasi dan kolaborasi. Sementara, manajer yang mendapat feedback workshop dan executive coaching menunjukkan peningkatan keefektifan peratingan dibandingkan manajer yang tidak menerima executive coaching. Luthans dan Peterson (2003) melaporkan perihal yang sama bahwa mengenai adanya dampak positif antara executive coaching atas selfawareness.

H2: Taktik pengaruh proaktif kepala penjualan pada tipe kepemimpinan 
transformasional dengan executive coaching lebih baik dibandingkan dengan taktik pengaruh proaktif kepala penjualan tanpa executive coaching.

Efektivitas Pemberian Executive Coaching Pada Tipe Kepemimpinan Transaksional

Menurut Bycio et al. (1995) kepemimpinan transaksional merupakan tipe kepemimpinan dimana pemimpin memberikan perhatian yang menekankan pada transaksi interpersonal yang terjadi pada pimpinan dengan anak buah melalui pelibatan hubungan pertukaran. Pertukaran yang terjadi tersebut berlandaskan kesepakatan tentang sasaran kerja yang telah diklasifikasi, batasan kerja, pemberian tugas kerja, dan penghargaan.

Giacobbi (2000) berpendapat bahwa coachability ditandai oleh antara lain motivasi untuk meningkatkan keterampilan, rasa ingin tahu, keterbukaan terhadap pembelajaran, dan kepercayaan dan rasa hormat terhadap pelatih dan atau proses pelatihannya. Shannahan, Bush dan Shannahan (2013) menerapkan konsep coachability atletik untuk penjualan dimana konsep penjual coachability sebagai tahapan penjual harus memiliki sifat terbuka untuk mencari, menerima, dan menggunakan sumber daya eksternal untuk meningkatkan kinerja penjualan mereka dalam konteks personal selling.

H3: Taktik pengaruh proaktif kepala penjualan pada tipe kepemimpinan transaksional dengan executive coaching lebih baik dibandingkan dengan taktik pengaruh proaktif kepala penjualan tanpa executive coaching.

\section{Metode}

\section{Subyek Eksperimen}

Partisipan dalam eksperimen terdiri dari sales head dan key account head di perusahaan otomotif multinasional yang sehari-hari memiliki tugas untuk menjual serta memimpin tenaga penjual untuk melakukan penjualan di Jakarta. Total subjek untuk semua sel adalah 96 orang kepala penjualan.

\section{Desain Penelitian}

Penelitian ini mempergunakan eksperimen lapangan (field experiment) sebagai metode untuk melakukan investigasi empiris mengenai pengaruh yang ditimbulkan dari adanya perlakukan executive coaching pada luaran kerja yang ditunjukkan dari capaian jumlah penjualan kepala penjualan secara personal.

Studi ini menggunakan mixed-factorial design $2 \times 2$ between-within subject sebagai pendekatan desain penelitian. Executive coaching menjadi faktor awal yang meliputi dua level yaitu ada executive coaching dan tidak ada executive coaching dan dilanjutkan tipe kepemimpinan sebagai faktor kedua yang juga meliputi dua level yaitu transformasional dan transaksional.

\section{Variabel dan Perlakuan}

Executive coaching serta tipe kepemimpinan merupakan variabel bebas yang dalam studi ini memperoleh perlakukan. Studi ini menggunakan executive coaching berbentuk intervensi MSF yang tersistematis dengan tujuan mencapai peningkatan profesionalitas keterampilan, kesadaran interpersonal, serta efektivitas personal (Kampa-Kokesch dan Anderson, 2001). Pemberian perlakuan executive coaching dilakukan melalui workshop yang merupakan multisource feedback yang dalam hal ini dilakukan oleh seorang eksekutif. Studi ini hanya akan difokuskan pada dua tipe kepemimpinan yang berkembang pesat (Ratnamiasih dan Warenih, 2014) yang telah dikembangkan oleh Bass (1990) dalam Locander et al (2002) yaitu kepemimpinan transformasional dan kepemimpinan transaksional yang dijalankan oleh manager khususnya bidang Human Resource dan Development.

Variabel dependen adalah luaran kerja yang pengukurannya dilakukan melalui proactive influence tactis yang dikembangkan oleh Kochanowski et al. (2010). Indikator-indikator variabel dependen tersebut antara lain terdiri dari rational persuasion, inspirational appeals, colaboration dan consultation. 
Tabel 1. Hasil Uji Komparatif pada Tipe Kepemimpinan Transformasional dan Transaksional

\begin{tabular}{l}
\hline \\
Equal variances assumed \\
\cline { 2 - 2 } Equal variances not assumed \\
\hline Sumber: Data Primer Diolah, 2018 \\
Teknik Analisis \\
Teknik analisis dalam studi ini dilakukan \\
tiga pendekatan, yaitu: Uji \\
melalui Tha \\
Independent Sample t Test, Uji Paired t Test, \\
dan Uji Wilcoxon. Uji independen Sample t \\
Test dilakukan untuk melakukan pengujian \\
perbedaan pada tipe kepemimpinan \\
transformasional dan transaksional. Uji \\
independent sample t test ini dilakukan bila \\
asumsi normalitas mampu terpenuhi. Uji \\
Paired t Test ditujukan untuk melakukan \\
pembuktian mengenai efektifitas perlakuan \\
yang dilakukan terhadap obyek yang belum \\
diberi perlakuan maupun yang sudah \\
diberikan perlakukan. Uji Paired t Test akan \\
dapat digunakan apabila asumsi normalitas \\
dapat terpenuhi. Uji Wilcoxon dilakukan \\
untuk membuktikan efektifitas suatu \\
perlakuan pada obyek yang belum diberi \\
perlakuan dengan yang diberi perlakukan jika \\
distribusi data penelitian tidak memenuhi \\
asumsi normalitas.
\end{tabular}

\section{Hasil}

Analisis Komparatif pada Tipe Kepemimpinan Transformasional dan Transaksional

Uji statistik yang dilakukan pada tahapan ini ditujukan untuk membuktikan ada atau tidaknya perbedaan yang signikan secara empiris antara kepemimpinan transformasional dan kepemimpinan transaksional. Uji independent sample t test merupakan pendekatan statistic yang dipilih untuk tujuan ini.

Hasil signifikansi nilai Levene's Test for Equality of Variance adalah sebesar 0,303 sehingga dapat disimpulkan bahwa data memiliki variance yang homogen. Merujuk pada nilai probabilitas dari Levene's Test for Equality of Variance maka pengujian pada perbedaan kepemimpinan transformasional dan transaksional dilakukan melalui analisis terhadap nilai probabilitas pada nilai Equal Variance Assumed dengan nilai probabilitas sebesar 0,000 yang lebih kecil dari 0,05 sehingga memperoleh kesimpulan bahwa terdapat perbedaan yang nyata antara kepemimpinan transformasional dan transaksional.

Analisis Komparatif Efektifitas Executive Coaching pada Tipe Kepemimpinan Transformasional

Tahapan ini memiliki tujuan untuk melakukan uji statistik dengan menggunakan data empiris untuk mengetahui ada atau tidaknya perbedaan antara kepemimpinan transformasional sebelum diberikan

Tabel 2. Hasil Uji Komparatif Sebelum Executive Coaching dan Sesudah Executive Coaching pada Tipe Kepemimpinan Transformasional

\begin{tabular}{lcccc}
\hline \multirow{2}{*}{$\begin{array}{c}\text { Dimensi } \\
\text { Kepemimpinan }\end{array}$} & \multicolumn{2}{c}{ Asumsi Normalitas } & \multicolumn{2}{c}{ Uji Komparatif } \\
\cline { 2 - 5 } & Signifikasi & Distribusi Data & Signifikansi & Pengujian Hipotesis \\
\hline Rational Persuasion & 0,005 & Tidak Normal & 0,000 & Diterima \\
\hline Inspirational Appeal & 0,097 & Normal & 0,815 & Ditolak \\
\hline Collaboration & 0,065 & Normal & 0,026 & Diterima \\
\hline Consultation & 0,118 & Normal & 0,024 & Diterima \\
\hline Transformasional & 0,762 & Normal & 0,000 & Diterima \\
\hline
\end{tabular}

Sumber: Data Primer Diolah, 2018 
perlakukan dengan executive coaching dengan kepemimpinan transformasional yang sudah diberikan perlakuan.

Tabel 3. Perubahan Tipe Kepemimpinan Transformasional Sebelum dan Sesudah Perlakuan Executive Coaching

\begin{tabular}{lcc}
\hline $\begin{array}{c}\text { Dimensi } \\
\text { Kepemimpinan }\end{array}$ & $\begin{array}{c}\text { Sebelum } \\
\text { Executive } \\
\text { Coaching }\end{array}$ & $\begin{array}{c}\text { Sesudah } \\
\text { Executive } \\
\text { Coaching }\end{array}$ \\
\hline $\begin{array}{l}\text { Rational } \\
\text { Persuasion }\end{array}$ & 59,58 & 78,08 \\
\hline Collaboration & 81,25 & 86,63 \\
\hline Consultation & 78,33 & 84,13 \\
\hline Transformasional & 72,39 & 79,96 \\
\hline
\end{tabular}

Sumber: Data Primer Diolah, 2018

Pengujian komparatif yang dilakukan pada berbagai tipe kepemimpinan untuk kepemimpinan transformasional sebelum diberi perlakuan executive coaching dengan yang sesudah diberi perlakuan menunjukkan bahwa executive coaching tidak terbukti meningkatkan inspirational appeal artinya, baik yang diberikan coaching maupun tidak diberikan coaching tidak ada perbedaan dalam inspirasional appeal. Namun, tidak demikian hasilnya pada tipe kepemimpinan yang lain. Executive coaching terbukti efektif meningkatkan tipe kepemimpinan dengan rational persuasion, collaboration, consultation, dan transformasional.

Hasil analisis deskriptif dalam tabel 3 memberikan informasi bahwa executive coaching efektif meningkatkan kinerja manager penjualan yang memiliki tipe kepemimpinan transformasional. Hal ini dibuktikan pada hasil capaian penjualan para manager penjualan setelah diberikan executive coaching yang meningkat.

Analisis Komparatif Efektifitas Executive Coaching pada Tipe Kepemimpinan Transaksional

Uji statistik pada tahapan ini bertujuan untuk melakukan pengujian empiris mengenai ada atau tidaknya perbedaan pada kepemimpinan transaksional sebelum diberikan perlakukan dengan executive coaching dengan kepemimpinan transaksional yang sudah diberikan perlakuan.

Tabel 5. Perubahan Tipe Kepemimpinan Transaksional Sebelum dan Sesudah Perlakuan Executive Coaching

\begin{tabular}{lcc}
\hline $\begin{array}{c}\text { Dimensi } \\
\text { Kepemimpinan }\end{array}$ & $\begin{array}{c}\text { Sebelum } \\
\text { Executive } \\
\text { Coaching }\end{array}$ & $\begin{array}{c}\text { Sesudah } \\
\text { Executive } \\
\text { Coaching }\end{array}$ \\
\hline Rational & 73,96 & 80,83 \\
\hline Inspirational & 72,92 & 80,42 \\
\hline Transaksional & 61,30 & 69,89 \\
\hline Sumber: Data Primer Diolah, 2018 \\
\multicolumn{3}{c}{ Uji komparatif yang dilakukan pada } \\
berbagai tipe kepemimpinan untuk \\
kepemimpinan transaksional sebelum diberi \\
perlakuan executive coaching dengan yang \\
sesudah diberi perlakukan menunjukkan \\
bahwa executive coaching tidak terbukti \\
meningkatkan tipe kepemimpinan \\
collaboration dan consultation artinya, baik \\
yang diberikan coaching maupun tidak \\
diberikan coaching tidak ada perbedaan \\
dalam tipe kepemimpinan collaboration dan
\end{tabular}

Tabel 4. Hasil Uji Komparatif Sebelum Executive Coaching dan Sesudah Executive Coaching pada Tipe Kepemimpinan Transaksional

\begin{tabular}{lcccc}
\hline \multirow{2}{*}{$\begin{array}{c}\text { Dimensi } \\
\text { Kepemimpinan }\end{array}$} & \multicolumn{2}{c}{ Asumsi Normalitas } & \multicolumn{2}{c}{ Uji Komparatif } \\
\cline { 2 - 5 } & Signifikasi & Distribusi Data & Signifikansi & Pengujian Hipotesis \\
\hline Rational Persuasion & 0,116 & Normal & 0,018 & Diterima \\
\hline Inspirational Appeal & 0,097 & Normal & 0,023 & Diterima \\
\hline Collaboration & 0,171 & Normal & 0,129 & Ditolak \\
\hline Consultation & 0,196 & Normal & 0,058 & Ditolak \\
\hline Transformasional & 0,497 & Normal & 0,000 & Diterima \\
\hline
\end{tabular}

Sumber: Data Primer Diolah, 2018 
consultation. Namun, tidak demikian hasilnya pada tipe kepemimpinan yang lain. Executive coaching terbukti efektif meningkatkan tipe kepemimpinan rational persuasion, inspirational appeal, serta kepemimpinan transformasional itu sendiri.

Analisis deskriptif dalam tabel 5 mengandung informasi bahwa executive coaching efektif meningkatkan kinerja manager penjualan yang memiliki tipe kepemimpinan transaksional. Hal ini dibuktikan pada hasil capaian penjualan para manager penjualan setelah diberikan executive coaching yang meningkat.

\section{Pembahasan}

Hasil studi ini menunjukkan bahwa executive coaching menghasilkan luaran yang lebih efektif pada kepemimpinan transformasional dibandingkan kepemimpinan transaksional. Pada kepemimpinan transformasional, taktik collaboration dan consultation pada kepemimpian transformasional memiliki nilai lebih tinggi setelah dilakukan executive coaching. Sedangkan pada kepemimpinan transaksional taktik rational dan inspirational memiliki nilai yang lebih tinggi setelah dilakukan executive coaching. Hasil penelitian ini menunjukkan bahwa secara empiris praktek executice coaching yang diberikan oleh manager akan memberikan luaran yang lebih efektif apabila pimpinan memiliki tipe atau gaya kepemimpinan transformasional dibandingkan dengan kepemimpinan transaksional. Temuan penelitian ini menjadi bukti empiris yang menguatkan teori bahwa tipe kepemimpinan transformasional di lingkungan kerja yang dinamis memberikan dampak kinerja yang efektif bagi karyawan dan efektifitas bagi organisasi. Hasil studi ini juga sejalan dengan penelitian Nieminen (2013) yang menyatakan bahwa luaran kerja yang dicapai manajer yang memperoleh perlakukan executive coaching menjadi meningkat signifikan jika dibandingkan luaran kerja manajer yang tidak memperoleh perlakukan executive coaching. Temuan ini menunjukkan bahwa aktifitas yang dilakukan dalam executive coaching memberikan manfaat penting bagi pimpinan untuk meraih pencapaian organisasi (DeNisi dan Kluger 2000; Kochanowski et al. 2010). Luthans dan Peterson (2003) juga memperoleh temuan yang sama mengenai adanya pengaruh yang positif dari adanya executive coaching. Temuan ini pun sejalan dengan studi Bogler (2001) bahwa motivasi dapat ditingkatkan oleh kepemimpinan transformasional kepuasan kerja, dan komitmen (Koh 1990). Oleh sebab itu, menurut Leithwood (1994), dalam proses atau sistem pendidikan kepemimpinan transformasional merupakan pendekatan yang efektif dalam.

Program executive coaching membantu membangun perilaku/habit baru di dalam organisasi dan membawa organisasi kepada sustainable superior performances. Sebagai pemimpin membantu pemimpin lain dalam memimpin proses yang membuat tim dan organisasi mampu mencapai hasil yang hebat dan belum pernah dicapai sebelumnya. Executive coaching membantu mengarahkan dan mengubah cara pemimpin dalam memimpin untuk mengikut sertakan timnya, supaya mampu meningkatkan hasil yang dicapai. Sebagai individu dapat memahami hal-hal yang perlu dikerjakan dalam rangka pencapaian tujuan bersama, menjadi karyawan yang lebih produktif dengan fokus kepada pekerjaan yang mendukung pencapaian tujuan organisasi. Belajar menggunakan proses dan sistem untuk fokus kepada pencapaian tujuan, membawa ide baru yang lebih baik kepada tim dan organisasi sehingga terjadi proses perbaikan secara terus-menerus.

Tipe kepemimpinan transformasional dengan executive coaching memiliki dampak terhadap taktik pengaruh proaktif dalam hal rational persuasion, collaboration dan consultatif. Hal ini menarik karena keselarasan dua ketrampilan tersebut tidaklah mudah untuk dipraktekkan. Kolaborasi ketrampilan tersebut menjadi alat untuk mencapai tujuan organisasi khususnya perusahaan yang diteliti, oleh karena itu budaya yang telah dibangun sangat menunjang pelaksanaan tersebut. Nilai pertama yang sangat penting dan menjadi dasar adalah integritas dan kejujuran yang merupakan keselarasan, kerendahan hati, dan keberanian. Keselarasan: hidup dengan nilai- 
nilai dan keyakinan. Melakukan apa yang dikatakan. Rendah hati: prinsip yang dipegang kukuh, terlebih menghadapi saat sulit. Hal yang benar lebih diutamakan, dibanding menjadi pihak yang paling benar. Keberanian: bertindak sesuai pada prinsip. Anda melakukan hal yang benar, terutama ketika hal itu sangat sulit dilakukan. Maka nilai integritas dan kejujuran adalah melakukan kegiatan atau tindakan dengan penuh komitmen, konsisten, tanggung jawab dan jujur, meskipun berada dalam keadaan sulit dengan berfokus pada perusahaan sesuai dengan kebijakan perusahaan yang berlaku.

Perlakukan executive coaching terhadap tipe kepemimpinan transaksional memiliki dampak yang tepat terhadap taktik pengaruh proaktif. Karena rational persuasion, menekankan pada penggunaan argumen yang logis dan bukti nyata yang memberikan petunjuk bahwa permintaan yang layak serta relevan bagi kepentingan pencapaian tujuan. Inspirational appeals, nilai dan cita-cita orang diperbandingkan untuk membangun emosi dalam rangka meraih komitmen. Dengan demikian, kinerja kepala penjualan benar meningkat ketika ditengarai dapat meningkat dengan pendekatan pembelajaran melalui executive coaching dan dipengaruhi oleh tipe kepemimpinan transaksional sebagai coach dalam proses pembelajaran.

\section{Kesimpulan}

Penelitian ini bertujuan untuk melakukan kajian secara empiris mengenai efektifitas executive coaching pimpinan dengan mempertimbangkan dua tipe kepemimpinan, yaitu kepemimpinan transformasional dan kepemimpinan transaksional. Simpulan dari hasil penelitian ini, yaitu: (1) Executive coaching mampu mendorong bawahan untuk menghasilkan kinerja penjualan lebih tinggi pada pemimpin yang memiliki gaya kepemimpinan transformasional dibandingkan kepemimpinan transaksional; (2) Executive coaching tidak terbukti meningkatkan dimensi inspirational appeal pada tipe kepemimpinan transformasional. Namun, executive coaching terbukti efektif meningkatkan dimensi rational persuasion, collaboration, dan consultation pada tipe kepemimpinan transformasional; dan (3)
Executive coaching tidak terbukti meningkatkan dimensi collaboration dan consultation pada tipe kepemimpina transaksional. Namun, executive coaching terbukti efektif meningkatkan dimensi rational persuasion dan inspirational appeal pada tipe kepemimpinan transaksional.

\section{Saran}

Executive coaching yang diberikan oleh pimpinan dengan menggunakan pendekatan gaya kepemimpinan transformasional secara empiris mampu menghasilkan luaran yang lebih efektif jika dibandingkan dengan pemimin yang menerapkan gaya kepemimpinan transaksional. Artinya, executive coaching dengan tipe kepemimpinan transformasional mampu memberi pengaruh dalam meningkatkan luaran kinerja, terlebih pada sales head dan key account head.

Merujuk pada hasil penelitian ini maka executive coaching merupakan treatment atau pendekatan yang perlu dilakukan untuk mendorong peningkatan luaran kinerja yang dicapai oleh bawahan. Namun, untuk menghasilkan executive coaching yang lebih efektif maka pemimpin perlu menggunakan gaya kepemimpinan transformasional. Adapun cara pelatihan yang dipergunakan dalam peningkatan executive coaching dengan tipe kepemimpinan transformasional yaitu melalui pemberian proses pembelajaran, antara lain penggunaan kata proaktif, komunikasi yang baik, penggunaan umpan balik dalam rangka peningkatan kepercayaan pada coachee. Virtual coaching dilakukan melalui email, bbm, sms, wa dan yang lain. Penggunaan kata dalam tulisan untuk memberikan dukungan personel dalam mengungkapkan pikiran. Penulisan kata memberikan peluang pemahaman oleh coachee, sehingga tanggapan yang diberikan sesuai harapan. Proses ini mendukung terhadap coaching yang memiliki hasil maksimal.

Pemanfaatan alat-alat yang relevan dengan virtual yang seringkali hanya dipakai sebagai komunikasi yang berkaitan dengan informasi, perintah dan bahkan komplain. Melalui penelitian ini maka di dimanfaatkan 
perusahaan untuk mengembangkan karyawan yaitu metode virtual coaching dan selaras dengan budaya yang dikembangkan yaitu improvement continuously. Pengembangan budaya untuk meningkatkan pelayanan dan maksimasi kompetensi bawahan dan pimpinan. Hal ini sangat menarik karena ke depan akan berdampak pada jumlah karyawan, sehingga perusahaan sudah melakukan efisensi dan efektifitas terhadap pekerjaan. Penggunaan virtual coaching ini juga bisa menjadi data untuk pengukuran kinerja karyawan, karena melalui virtual ini pimpinan yang lebih atas bisa melakukan tracking terhadap coaching yang dilakukan di level bawahnya. Berkaitan dengan efisiensi dan efektivitas dalam bekerja, merupakan dukungan terhadap budaya yang dikembangkan perusahaan tentang maksimum kontribusi. Jika setiap karyawan mampu memaksimalkan kontribusinya terhadap perusahaan maka dampak yang diperoleh perusahaan yang berkaitan dengan finansial akan semakin besar, dan hal ini berimbas pada remunerasi dan bonus bagi karyawan. Virtual coaching memiliki dampak bagi growth and sustainable.

\section{Daftar Referensi}

Bogler, R. 2001. The influence of leadership style on teacher job satisfaction. Educational Administration Quarterly, Vol. 37, pp. 662-83.

Bycio, P., Hackett, R.D., \& Allen, J.S. 1995. Further assessments of Bass's (1985) conceptualization of transactional and transformational leadership. Journal of Applied Psychology, 80(4): 468-478

Cohen, S.G dan D.E Bailey. 1997. What Makes Teams Work: Group Effectiveness Research from the Shop Floor to the Executive Suitel. Journal of Management. 23. 239-290.

DeNisi, A. S., \& Kluger, A. N. 2000. Feedback effectiveness: Can 360-degree appraisals be improved? Academy of Management Executive, 14 (1), 129-139.

Denison, D. R., dan Mishra, A. 1995. Toward a theory of organizational culture and effectiveness. Organizational Science, 6, 204-223.
Denison, D. R., Nieminen, L. R., dan L., Kotrb. 2003. Diagnosing organizational cultures: Aconceptual and empirical review of culture effectiveness surveys. European Journal of Work and Organizational Psychology

Feldman, D. C., dan M. J. Lankau. 2005. Executive coaching: A review and agenda for future research. Journal of Management 31: 829-848

Filipezak, R. 1998. The Executive Coach: Helper or healer? Training. 35

Giacobbi, P. 2000. The athletic coachability scale: Construct conceptualization and psychometric analyses. Doctoral dissertation. Knoxville: University of Tennessee.

Hackman, J.R dan R.E Walton. 1986. Leading Groups in Organization: Designing Effective Work Groups. Jossey Bass. San Fransisco.

Irawati, R dan Y. Liana, 2013. Pengaruh Gaya Kepemimpinan Transformasional dan Kepuasan Kerja terhadap Kinerja Pegawai. Jurnal Ilmiah ESI, 7 (3).

Joo, B. (2005). Executive coaching: A conceptual framework from an integrative review of practice and research. Human Resource Development Review, 4 (4), 462-488.

Kampa-Kokesch, S. dan M. Z. Anderson. 2001. Executive coaching: A comprehensive review of the literature. Consulting Psychology Journal: Practice \& Research 53 (4): 205-228

Kilburg, R.(1996). Toward a conceptual understanding and definition of executive coaching. Consulting Psychology Journal: Practice and Research, 48 (2), 134-144.

Kochanowski, S., C. F., Seifert dan G. Yukl. 2010. Using executive coaching to enhance the effects of behavioral feedback to managers. Journal of Leadership and Organizational Studies, 17: 363-369

Koh, W. 1990. An empirical validation of the theory of transformational leadership in secondary schools in Singapore. 
Unpublished doctoral dissertation, University of Oregon, Concordia.

Koontz, H dan C. Weihrich. 1990. Essentials of Management. McGraw Hill. New York.

Kozlowski, S.W.J., S.M Gully, P.P McHugh, E. Salas dan J Cannon-Bowers. 1996. A Dynamic Theory of Leadership and Team Effectiveness: Developmental and Task Contingent Leader Roles. Research in Personnel and Human Resource Management.

Leithwood, K. 1994. Leadership for schoolrestructuring. Educational Administration Quarterly. Vol. 30 No. 4: 498-518.

Locander, W. B., F. Hamilton, D. Ladik dan J. Stuart 2002. Developing a Leadership-Rich Culture: The Missing Link to Creating a Market-Focused Organization. Journal of MarketFocused Management. 5. 149-146

Luthans, F. J., dan S. J. Peterson. 2003. 360 degree feedback with systematic executive coaching: Empirical analysis suggests a winning combination. Human Resource Management: 42:243-256

Maulizar, S. Musnadi, dan M Yunus. 2012. Pengaruh Kepemimpinan Transaksional dan Transformasional terhadap Kinerja Pegawai Bank Syariah Mandiri Cabang Banda. Jurnal Ilmu Manajemen,

McCauley C. D, dan S. A. Hezlett. 2002. Individual development in the workplace. In Anderson N, Ones D, Sinangil HK, Viswesvaran C (Eds.), Handbook of industrial, work and organizational psychology, Vol. 1: Personnel psychology (pp. 313-335). Thousand Oaks, CA: Sage.

Muhardi dan M.R Siregar. 2013. Pengaruh Kepemimpinan Transformasional dan Transaksional Terhadap Kinerja Pegawai Badan Investasi dan Promosi Aceh. Jurnal Ekonomi Manajemen dan Bisnis, 1 (1). 99-117.

Nieminen, L., Smerek, R., Kotrba, L., dan Denison, D. (2013). What does an executive coaching intervention and facilitated multisource feedback? Effects on leader self-ratings and perceived effectiveness. Human Resource Development Quarterly, 24(2), 145-176

Pierce, J. L. dan J. W. Newstrom. 2006. Leaders and The Leadership Proces: Readings, Self Asesments \& Aplications. McGraw-Hil Companies, Inc. New York

Pradana, M. A. 2013. Pengaruh Gaya Kepemimpinan Transformasional dan Transaksional Terhadap kinerja Pegawai PT Mustika Bahana Jaya Lumajang. Jurnal Ilmu Manajemen, 4 (2).

Quick, J. C dan M. Macik-Frey. 2004. Behind the mask: Coaching through deep interpersonal. Consulting Psychology Journal: Practice and Research 56: 67-74

Ratnamiasih, Ina dan Warenih, 2014. Pengaruh Kepemimpinan Transformasional dan Transaksional pada Kinerja Pegawai Bappeda Kota Bandung. Trikonomika. 13 (2). 119-126.

Robbins, S. P. 2008. Perilaku Organisasi. Edisi Bahasa Indonesia, Alih Bahasa, Benyamin Molan. Jakarta: Indeks.

Seifert, B., Morris, S. A. and Bartkus, B. R. (2003). Comparing Big Givers and Small Givers: Financial Correlates of Corporate Philanthropy. Journal of Business Ethics, 45(3), pp. 195-211, https://doi.org/10.1023/A:10241994118 07

Shannahan K. L., A.J. Bush dan R. J. Shannahan. 2013. Are your salespeople coachable? How salesperson coachability, trait competitiveness and transformational leadership enhance sales performance. Journal of Academic Marketing Science. Vol.41

Sinclair, B. 1992. The Emergence of Strong Leadership in The 1980s House of Representatives. The Journal of Politics.

Yukl, G. A. 2009. Kepemimpinan Dalam Organisasi. PT Indeks. Jakarta

Zaccaro, S.J., A.L Rittman dan M.A Marks. 2001. Team Leadership. Leadership Quarterly. 